\begin{tabular}{|c|c|c|c|}
\hline Case Reports in & \multicolumn{2}{|c|}{ Case Rep Gastroenterol 2017;11:610-615 } & \multirow[b]{2}{*}{$\begin{array}{l}\text { Karger } \\
\text { Open access }\end{array}$} \\
\hline Gastroenterology & $\begin{array}{l}\text { DOI: 10.1159/000481164 } \\
\text { Publisned online: October 6, } 2017\end{array}$ & \begin{tabular}{|l|} 
The Author(s) \\
Published by S. Karger AG, Basel \\
www.karger.com/crg
\end{tabular} & \\
\hline & $\begin{array}{l}\text { This article is licensed under th } \\
\text { International License (CC BY-NC } \\
\text { Usage and distribution for comme }\end{array}$ & $\begin{array}{l}\text { nons Attribution-NonCommercial } 4.0 \\
\text { ger.com/Services/OpenAccessLicense). } \\
\text { uires written permission. }\end{array}$ & \\
\hline
\end{tabular}

\title{
Vanishing Tumor in a Liver Graft from a Hepatitis B Virus Surface Antigen-Positive Donor
}

\author{
Mayo Fuchino Kazuto Tajiri Masami Minemura Toshiro Sugiyama \\ Department of Gastroenterology, Toyama University Hospital, Toyama, Japan
}

\section{Keywords}

Inflammatory pseudotumor · Liver transplantation · Vanishing tumor

\begin{abstract}
We report a case of vanishing tumor considered as inflammatory pseudotumor (IPT) found in the liver after living donor liver transplantation (LDLT) from a hepatitis B virus surface antigen-positive donor. The radiological findings were similar to those of hepatocellular carcinoma (HCC). However, the tumor disappeared completely within several months and was suggested to have been an IPT. IPT is known to be associated with biliary duct operation or biliary infection, and it can show various enhancement patterns in radiological studies, sometimes resembling HCC. It should be considered in the differential diagnosis of a liver tumor in patients with LDLT.

(C) 2017 The Author(s)

Published by S. Karger AG, Basel
\end{abstract}

\section{Introduction}

Vanishing liver tumors, i.e., liver tumors with spontaneous resolution, are rarely observed, but a recognized entity that has been reported to occur widely from benign to malignant tumors [1]. Although the etiology of this unusual phenomenon remains unclear, hepatic adenoma, infantile hepatic hemangioendothelioma, hepatocellular carcinoma (HCC), lymphoma, and inflammatory pseudotumor (IPT) have been reported as vanishing tumors [1]. 
IPTs of the liver are fairly uncommon lesions [2-4]. In radiological findings, they can show various contrast enhancement patterns and often resemble primary or secondary liver cancer. In specific cases, particularly those with hepatitis virus infection, it is extremely difficult to establish a definite diagnosis by radiological imaging because the possibility of HCC cannot be ruled out [3-5].

To our knowledge, there has been only one report of IPT in a liver graft [6]. Furthermore, a case of IPT in a hepatitis B virus surface antigen (HBsAg)-positive liver graft has never been reported. We herein report a rare case considered as hepatic IPT after living donor liver transplantation (LDLT) from an HBsAg-positive donor.

\section{Case Presentation}

A 53-year-old man was referred to our hospital in 2014 for investigation of biliary enzyme elevation. In 1999, at the age of 38 years, he suffered from severe hepatitis due to acute hepatitis A accompanied by chronic hepatitis B. He underwent LDLT with a right lobe graft donated by his younger brother at a transplant center. The donor was HBsAg positive, but there was no other eligible donor. Therefore, LDLT from the HBsAg-positive donor was performed after approval by the institutional review board of the transplant center. After LDLT, the patient continued to be HBsAg and hepatitis B virus (HBV) DNA positive despite the use of anti-HBV immunoglobulin and nucleoside analogues (lamivudine and adefovir) because of appearing lamivudine-resistant HBV strain. He received tacrolimus as an immunosuppression after LDLT. He did not experience any acute cellular rejection. He had an iodinated contrast medium allergy.

Physical examination was normal except for the operation scar of LDLT. Laboratory investigations showed a hemoglobin level of $13.3 \mathrm{~g} / \mathrm{dL}$ and a white blood cell count of $3,480 / \mu \mathrm{L}$. The serum C-reactive protein level was slightly elevated to $0.49 \mathrm{mg} / \mathrm{dL}$ (normal range, <0.14). The results of biochemical analysis of the blood were total bilirubin $1.2 \mathrm{mg} / \mathrm{dL}$ (normal range, 0.4-1.5), aspartate aminotransferase $55 \mathrm{IU} / \mathrm{L}$ (normal range, 12-31), alanine aminotransferase $81 \mathrm{IU} / \mathrm{L}$ (normal range, 8-40), alkaline phosphatase 2,355 IU/L (normal range, 100-330), $\gamma$-glutamyl transpeptidase 1,413 IU/L (normal range, 11-73), carcinoembryonic antigen $6.0 \mathrm{ng} / \mathrm{mL}$ (normal range, <3.4), carbohydrate antigen 19-9 39 U/mL (normal range, <37.0), alpha-fetoprotein $1.9 \mathrm{ng} / \mathrm{mL}$ (normal range, <7.0), and des- $\gamma$-carboxy prothrombin $20 \mathrm{mAU} / \mathrm{mL}$ (normal range, $<40.0$ ). HBsAg, hepatitis B core antibody, and hepatitis $B$ e-antigen were all positive. Hepatitis $C$ antibody was negative. Liver biopsy from the background liver showed mild inflammation and fibrosis probably due to chronic hepatitis $\mathrm{B}$ and did not suggest rejection. Abdominal ultrasound (US) showed a low-echoic nodule at segment 5/6 (Fig. 1a). Biliary dilatation was not observed. Contrast-enhanced real-time ultrasound imaging with Sonazoid ${ }^{\circledR}$ (Daiichisankyo, Tokyo, Japan) showed that this nodule was hypervascular in the arterial phase (Fig. 1b), followed by a defect in the postvascular phase (Fig. 1c). These US findings suggested this tumor to be a solid tumor but not liver abscess, and the enhancement pattern was heavily suggestive of malignancy such as HCC. Magnetic resonance imaging (MRI) examination showed a $15-\mathrm{mm}$ mass in segment $5 / 6$ of the right lobe of the liver, with low intensity on T1-weighted image and high intensity on T2weighted as well as diffusion-weighted image. Dynamic contrast-enhanced MRI with gadolinium-ethoxybenzyl-diethylenetriamine pentaacetic acid (EOB-MRI) also showed hypervascularity in the arterial phase (Fig. 1d). In the hepatobiliary phase of EOB-MRI, the tumor showed low intensity, similar to findings in HCC (Fig. 1e). Although the tumor markers al- 
pha-fetoprotein and des- $\gamma$-carboxy prothrombin were not elevated, the mass was clinically diagnosed as HCC because the patient had chronic HBV infection. ${ }^{18} \mathrm{~F}$ fluoro-2-deoxy-Dglucose positron emission tomography (FDG-PET) was performed to exclude the possibility of metastatic liver tumor from other organ malignancy. It revealed abnormal uptake in the liver tumor but no abnormal uptake in other lesions (Fig. 1f), supporting the diagnosis of hepatic malignancy including HCC.

We referred the patient to the transplant center where his LDLT had been done to treat the tumor surgically. However, the tumor became unclear on EOB-MRI after 1 month (Fig. 2a, b). A structure showing high intensity on T1-weighted MRI image was found at the roots of the right hepatic biliary duct (Fig. 2c). A similar lesion was also retrospectively found on the initial MRI images (data not shown). Therefore, the patient was treated by percutaneous transhepatic cholangiodrainage and then biliary sludge was removed (Fig. 2d). We then followed him carefully. Six months after the first examination, the tumor had completely disappeared on EOB-MRI (Fig. 3a, b) and biliary sludge was not detected (Fig. 3c). We therefore considered the tumor as an IPT secondary to biliary tract infection due to biliaryjejunum reconstruction. The patient's clinical course was good and no recurrence was found for 3 years.

\section{Discussion}

IPTs of the liver are relatively rare and problematic in the differential diagnosis from HCC $[5,7]$. Histologically, they are characterized by proliferating fibrovascular tissue with infiltration of inflammatory cells. IPTs can show various contrast enhancement patterns because their vascularity ranges widely from avascular to hypervascular [7]. This variety of enhancement patterns is due to the pathological changes in the course of disease progression. It will become hypovascular when the tumor is dominated by fibrous tissue, and it will be hypervascular when the tumor is dominated by inflammatory cells [8]. Therefore, it is difficult to make a diagnosis based on imaging findings [9].

In our case, HCC was highly suspected at first because the patient was HBsAg positive and the findings from EOB-MRI and FDG-PET suggested malignancy of the liver. However, the tumor became unclear after 1 month and disappeared completely. This led us to a suspicion of IPT. Although HCC also has a possibility of spontaneous regression, the disappearance in our patient was too fast for HCC. Spontaneous regression and resolution of HCC without treatment is an extraordinarily rare phenomenon. It is related to tumor necrosis or autoinfarction [1]. Several mechanisms, including tumor ischemia, systemic inflammatory activation, temperance, drugs, and others, were reported to trigger this event [10]. Our patient experienced none of these events. In the present case, although histological confirmation could not be performed, IPT was suggested rather than HCC.

Previous studies reported that most patients with IPT had hepatobiliary tract diseases such as biliary stones, history of liver resection, cholangitis, liver abscess, or hepatobiliary malignancy $[2,11]$. These findings support the underlying infectious condition as etiology of IPTs. Our patient had a history of LDLT with biliary-jejunum reconstruction which might have been the cause of the IPT. IPTs of the liver have a good prognosis with conservative management, usually resolving spontaneously. Once they are diagnosed, surgical resection is not necessary [5]. Histological confirmation should be considered if in doubt.

In conclusion, IPTs of the liver are often difficult to distinguish from malignant tumors. In particular, they are associated with biliary duct operation and biliary infection. However, 
Fuchino et al.: Vanishing Tumor in a Liver Graft from a Hepatitis B Virus Surface AntigenPositive Donor

IPTs have a good prognosis, so they should be considered in the differential diagnosis of a liver mass with an operation including LDLT or biliary infection antecedent.

\section{Statement of Ethics}

The authors have no ethical conflicts to disclose. Written informed consent was obtained from the patient for publication of this case report.

\section{Disclosure Statement}

The authors have no conflicts of interest to disclose.

\section{References}

1 Peddu P, Huang D, Kane PA, Karani JB, Knisely AS: Vanishing liver tumours. Clin Radiol 2008;63:329339.

2 Koea JB, Broadhurst GW, Rodgers MS, McCall JL: Inflammatory pseudotumor of the liver: demographics, diagnosis, and the case for nonoperative management. J Am Coll Surg 2003;196:226-235.

-3 Guarino B, Catalano O, Corvino A, Corvino F, Amore A, Petrillo A: Hepatic inflammatory pseudotumor: educational value of an incorrect diagnosis at contrast-enhanced ultrasound. J Med Ultrason (2001) 2015;42:547-552.

4 Calomeni GD, Ataide EB, Machado RR, Escanhoela CA, Costa LB, Boin IF: Hepatic inflammatory pseudotumor: a case series. Int J Surg Case Rep 2013;4:308-311.

5 Akatsu T, Wakabayashi G, Tanimoto A, Kameyama K, Kitajima M: Inflammatory pseudotumor of the liver masquerading as hepatocellular carcinoma after a hepatitis B virus infection: report of a case. Surg Today 2006;36:1028-1031.

6 Yoshiya S, Ikegami T, Yoshizumi T, Wang H, Harada N, Yamashita Y, Nishie A, Shirabe K, Oda Y, Maehara Y: Fairly rare de novo inflammatory pseudotumor in a graft after living donor liver transplantation. Liver Transpl 2014;20:616-618.

7 Ke Q, Fan L, Duan X, He Z, Zheng S: Inflammatory pseudotumor mimicking primary hepatic malignant tumor with hepatitis B virus-related cirrhosis: a case report. Oncol Lett 2013;6:550-552.

8 Yoshikawa J, Matsui O, Kadoya M, Gabata T, Arai K, Takashima T: Delayed enhancement of fibrotic areas in hepatic masses: CT-pathologic correlation. J Comput Assist Tomogr 1992;16:206-211.

$\checkmark 9$ Iguchi H, Yamazaki H, Tsunoda H, Takahashi Y, Yokomori H: A case of inflammatory pseudotumor of the liver mimicking hepatocellular carcinoma on EOB-MRI and PET. Case Rep Med 2013;2013:594254.

$\gg 10$ Wang Z, Ke ZF, Lu XF, Luo CJ, Liu YD, Lin ZW, Wang LT: The clue of a possible etiology about spontaneous regression of hepatocellular carcinoma: a perspective on pathology. Onco Targets Ther 2015;8:395-400.

11 Park JY, Choi MS, Lim YS, Park JW, Kim SU, Min YW, Gwak GY, Paik YH, Lee JH, Koh KC, Paik SW, Yoo BC: Clinical features, image findings, and prognosis of inflammatory pseudotumor of the liver: a multicenter experience of 45 cases. Gut Liver 2014;8:58-63. 


\section{Case Reports in Gastroenterology}
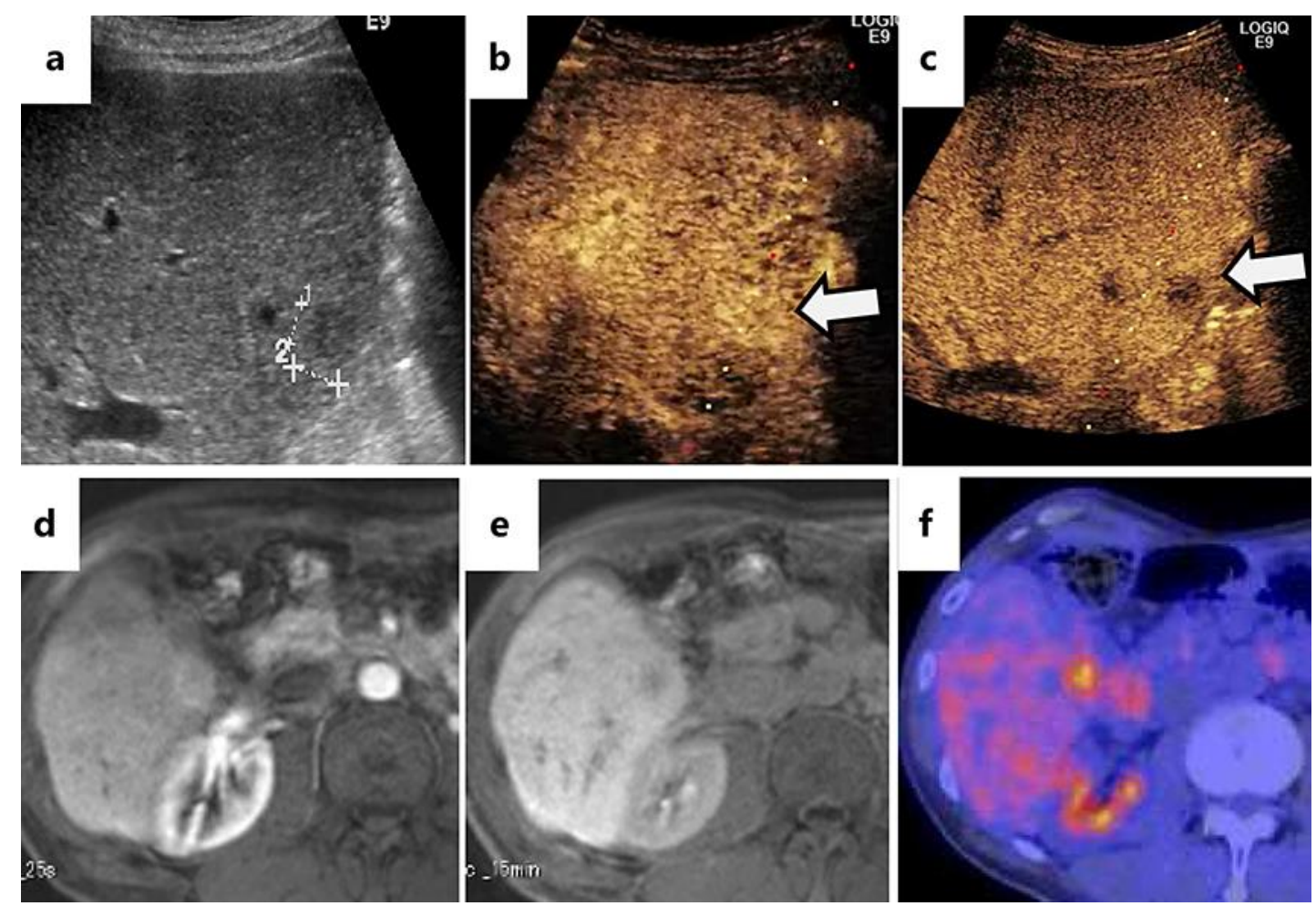

Fig. 1. a Ultrasound showed a low-echoic nodule at segment 5/6. b Contrast-enhanced real-time ultrasound using Sonazoid ${ }^{\circledR}$ demonstrated that the nodule was hypervascular in the arterial phase. The arrow indicates the tumor. c The tumor showed a defect in the Kupffer phase. The arrow indicates the tumor. d, e Gadolinium-ethoxybenzyl-diethylenetriamine pentaacetic acid-enhanced magnetic resonance images. d The tumor showed hypervascularity in the arterial phase. e The tumor showed low intensity in the hepatobiliary phase. f $18 \mathrm{~F}$ fluoro-2-deoxy-D-glucose positron emission tomography. The tumor showed fluorodeoxyglucose uptake. 
Fuchino et al:: Vanishing Tumor in a Liver Graft from a Hepatitis B Virus Surface AntigenPositive Donor
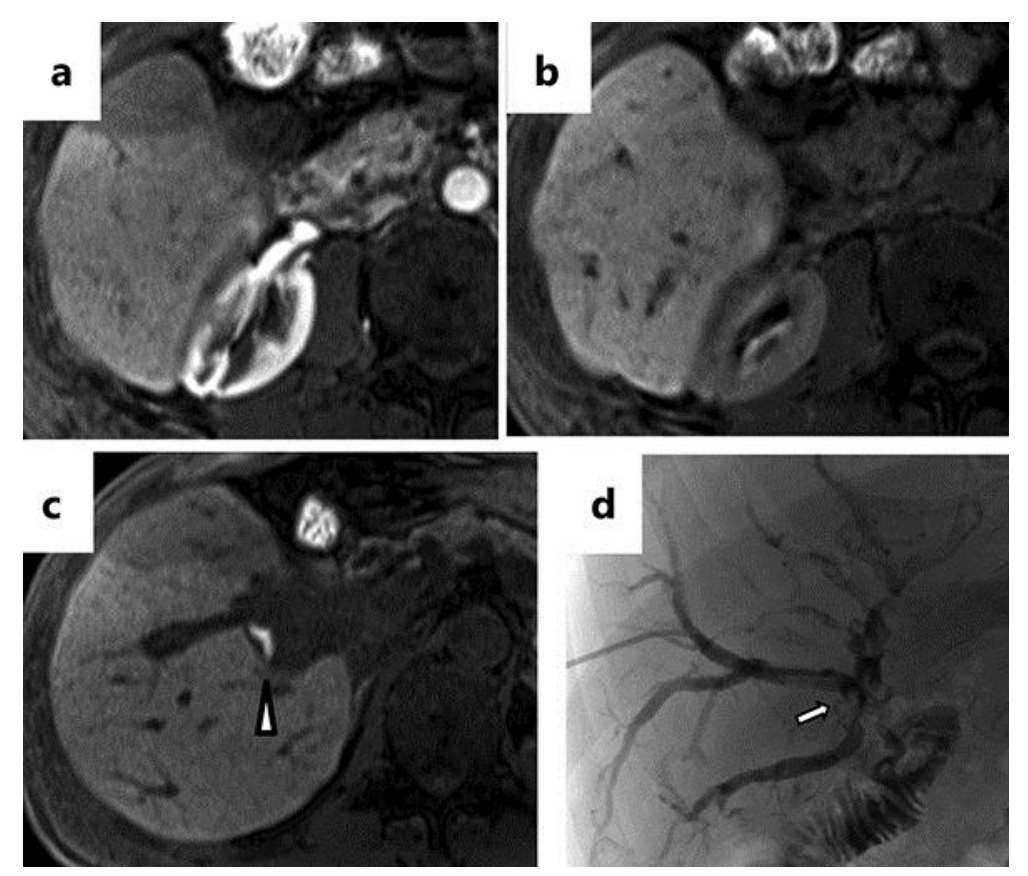

Fig. 2. a, b Gadolinium-ethoxybenzyl-diethylenetriamine pentaacetic acid-enhanced magnetic resonance imaging 1 month after the first examination. a The tumor was unclear in the arterial phase. $\mathbf{b}$ The tumor had decreased in size in the hepatobiliary phase. c A lesion showing high intensity on T1-weighted MRI was found at the roots of the right hepatic duct (arrowhead). d Sludge was detected at the roots of the right hepatic duct (arrow).
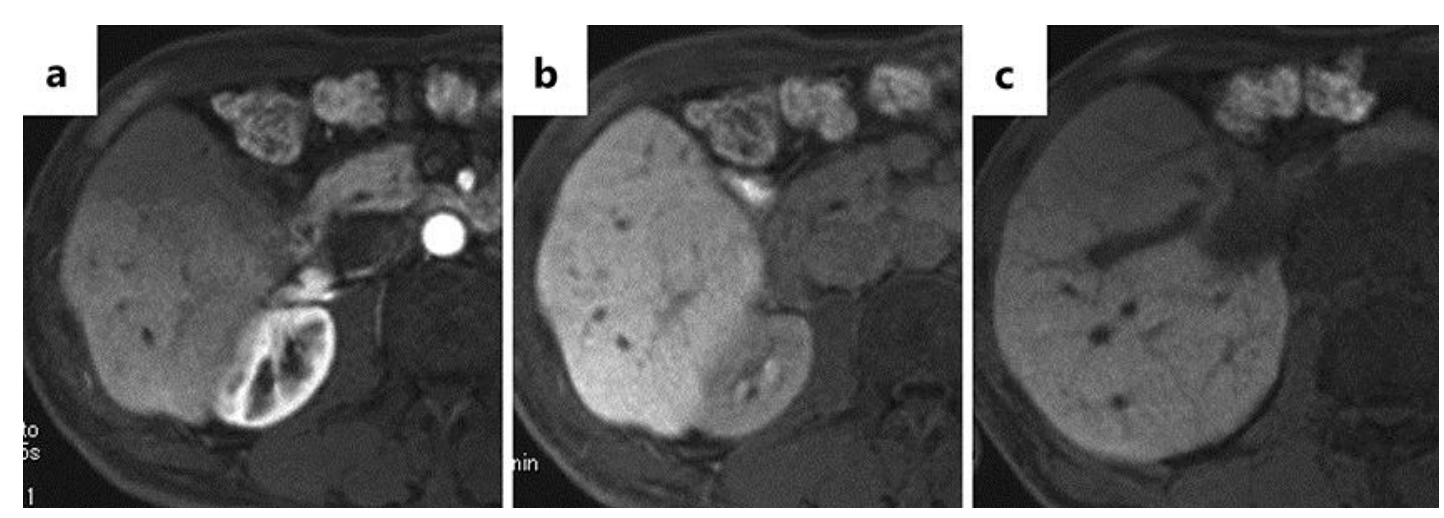

Fig. 3. a-c Gadolinium-ethoxybenzyl-diethylenetriamine pentaacetic acid-enhanced magnetic resonance imaging 6 months after the first examination. a The tumor had completely disappeared in the arterial phase. $\mathbf{b}$ The tumor had completely disappeared in the hepatobiliary phase as well. c Sludge had disappeared at the roots of the right hepatic duct on T1-weighted image. 